\title{
Welcome to volume 12 of the journal Future Microbiology
}

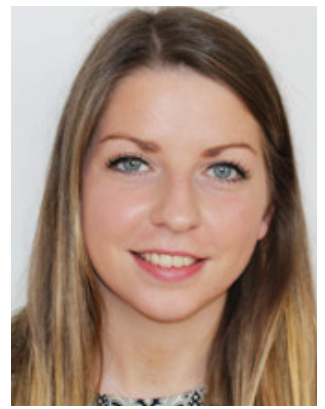

Frances Adlam ${ }^{*, 1}$

\author{
"I look forward to working with some of you in the coming \\ year and to continuing to publish the high-quality content that \\ has secured Future Microbiology as a prominent journal in the \\ microbiology field.”
}

Future Microbiology would like to wish all of its readers a happy new year and introduce you all to the 12th volume of the journal! 2016 was another great year for Future Microbiology; we published some excellent papers from a range of experts in the field and it was also the 10th year anniversary of the journal. I would like to start 2017 by thanking our Editorial Board, readers and contributing authors for their continued support to date. Please see below for our content highlights and updates from the past year.

\section{Content highlights 2016}

Future Microbiology's top read article of 2016 (as of October 2016) was a review article entitled 'T2MR and T2Candida: novel technology for the rapid diagnosis of candidemia and invasive candidiasis' written by a member of Future Microbiology's editorial board, Michael A Pfaller, along with his institutional colleague Thomas J Lowery from T2 Biosystems (MA, USA) and Donna M Wolk from Geisinger Health Systems (PA, USA). Nosocomial candidiasis infections continue to pose an important health threat to the immunocompromised and critically ill. Therefore, rapid diagnosis of infection is essential to avoid fatalities. This paper considers the use of the T2 magnetic resonance approach to detecting Candida species, including invasive candidiasis, and discusses its potential role in antifungal stewardship [1].

The second most read article was a primary research piece that aimed to characterize the EndoSlike enzymes in Streptococcus dysgalactiae subspecies dysgalactiae, a bacterium responsible for causing a range of human diseases. Written by Shadnezhad et al., this article reports on the discovery of two new enzymes, EndoSd/EndoS2d, and provides further understanding of the mechanisms behind bacterial evasion of the host immune system [2].

Antimicrobial resistance is an increasing public health threat. Two more of our top-read articles address this issue and provide potential solutions to get this resistance under control. In a perspective piece by Dik et al., the authors present an antimicrobial, infection prevention and diagnostic stewardship model to serve as a blueprint to enforce innovative, integrative infection management [3]. Further to this, a short opinion piece by Gandra et al. discusses the importance of private sector laboratories playing their role in public health surveillance of antimicrobial resistance [4].

\section{KEYWORDS}

- antimicrobial resistance

- candidemia $\bullet$ gut

microbiota $\bullet$ microbiology

- Streptococcus dysgalactiae

- vaccination 


\section{Top Altmetric articles}

We have been working with Altmetric since 2015 to help visualize where the articles we publish are having online impact. Therefore, a special acknowledgement goes to the following articles for receiving the highest Altmetric scores throughout Future Microbiology's 10 years of publication:

- Our highest score was a review article entitled: 'Polio vaccination: past, present and future' written by Bandyopadhyay et al. [5] - Altmetric score 68 ;

- Next was a research article entitled: 'The economic impact of rapid Candida species identification by T2Candida among high-risk patients' written by Bilir et al. [6] - Altmetric score 47;

- Following this, a perspective piece entitled: 'A multifaceted 'omics' approach for addressing the challenge of antimicrobial resistance' written by Cohen et al. [7] - Altmetric score 34 ;

- A review entitled: 'The relationship between gut microbiota and weight gain in humans' written by Angelakis et al. [8] - Altmetric score 29.

\section{Reader demographic}

It is interesting to see the particular areas in the world where Future Microbiology's content has the highest readership (Figure 1). In 2016, our readers where primarily based in the USA and China (both 22\%), closely followed by other (Europe) (19\%) and Brazil (16\%). We are delighted to see our content reaching many areas around the globe and we hope this widespread reach continues in the coming years.

\section{Social media}

Future Microbiology is still active across the social media platforms: twitter (@fsgfmb) and LinkedIn [9]. Highlighting exciting and novel research in the microbiology field while also posting the journals highlights and newly published articles, we continue to enjoy collaborating with the experts in the field.

\section{Conclusion}

We are always grateful for any feedback the microbiology community wishes to share, whether it is recommendations of any 'hot topics' that should be featured or where you see the microbiology field heading. We welcome a range of unsolicited article types and would be happy to hear from you. In particular we are looking for submissions on:

- the molecular basis of microbial diseases;

- microbe-host interactions;

- overviews highlighting optimal therapeutic and diagnostic approaches, along with potential future options;

- the use of microbes in the treatment of disease and genetic engineering;

- summaries evaluating newly approved antimicrobial agents;

- pharmacoeconomics and cost-benefit issues in microbiology;

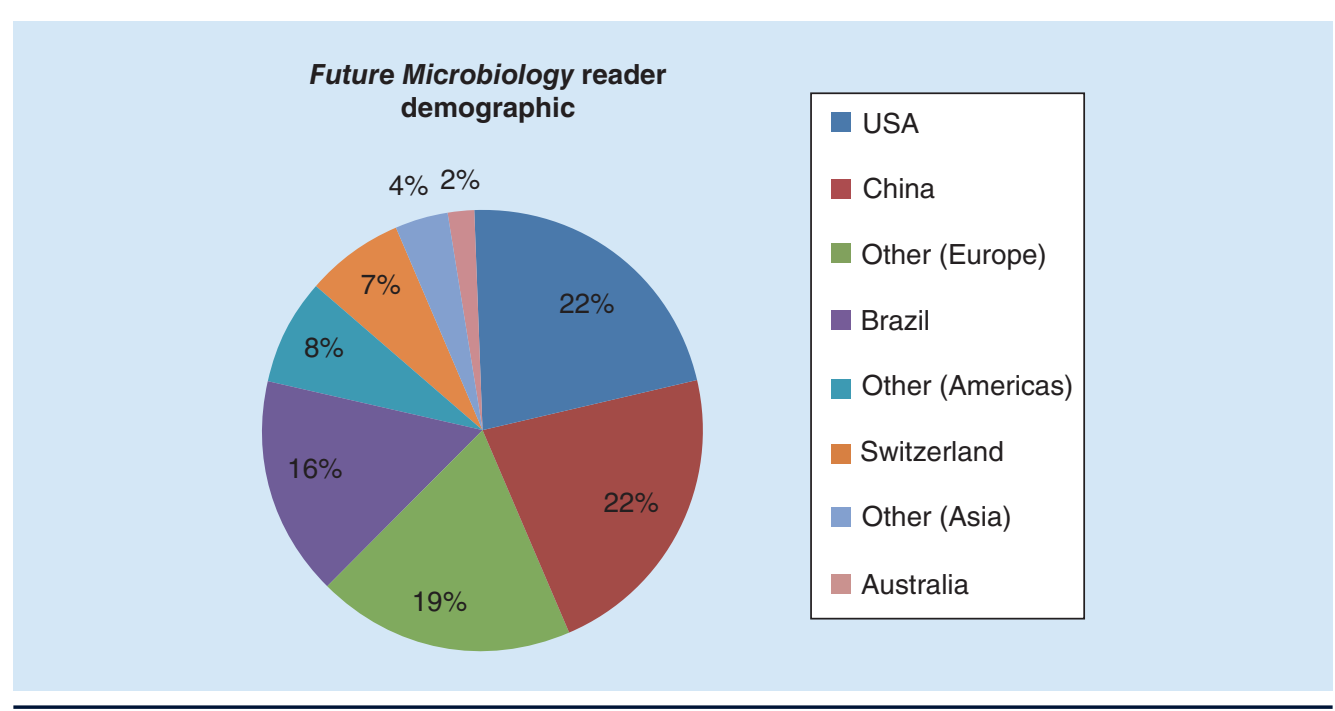

Figure 1. Proportion of readership demographics for Future Microbiology in 2016. 
- new and re-emerging microbes impacting human health;

- microbial genome research and the implications to higher organisms;

- microbes and cancer;

- epidemiologic studies and trends;

- the problem of drug resistance and potential methods to overcome this; and

- defense against the use of microbes in bioterrorism.
I look forward to working with some of you in the coming year and to continuing to publish the high-quality content that has secured Future Microbiology as a prominent journal in the microbiology field.

\section{Financial \& competing interests disclosure}

F Adlam is an employee of Future Medicine Ltd. The author has no other relevant affliations or financial involvement with any organization or entity with a financial interest in or financial conflict with the subject matter or materials discussed in the manuscript apart from those disclosed.

No writing assistance was utilized in the production of this manuscript.

\section{References}

1 Pfaller MA, Wolk DM, Lowery TJ. T2MR and T2Candida: novel technology for the rapid diagnosis of candidemia and invasive candidiasis. 11(1) 103-117 (2016).

2 Shadnezhad A, Naegeli A, Sjögren J et al. EndoSd: an IgG glycan hydrolyzing enzyme in Streptococcus dysgalactiae subspecies dysgalactiae. Future Microbiol. 11(6) 721-736 (2016).

3 Dik JH, Poelman R, Friedrich AW. An integrated stewardship model: antimicrobial, infection prevention and diagnostic (AID). Future Microbiol. 11(1) 93-102 (2016).

4 Gandra S, Merchant AT, Laxminarayan R. A role for private sector laboratories in public health surveillance of antimicrobial resistance. Future Microbiol. 11(6) 709-712 (2016).

5 Bandyopadhyay AS, Garon J, Seib K, Orenstein WA. Polio vaccination: past, present and future. Future Microbiol. 10(5) 791-808 (2015).

6 Bilir SP, Ferrufino CP, Pfaller MA, Munakata J. The economic impact of rapid Candida species identification by T2Candida among high-risk patients. Future Microbiol. 10 (7) 1133-1144 (2015).

7 Cohen A, Bont L, Engelhard D et al. A multifaceted 'omics' approach for addressing the challenge of antimicrobial resistance. Future Microbiol. 10(3) 365-376 (2015).

8 Angelakis E, Armougom F, Million M, Raoult $\mathrm{D}$. The relationship between gut microbiota and weight gain in humans. Future Microbiol. 7(1) 91-109 (2012).

9 Linkedin Group: Future Science Group Microbiology. https://www.linkedin.com/groups/8506116 